\title{
Socio-economic factors and their influences on scale efficiency of wheat farms
}

\author{
Muhammad Sadiq Hashmi ${ }^{1 *}$, Muhammad Asif Kamran², Khuda \\ Bakhsh $^{3}$, Muhammad Amjad Bashir ${ }^{4}$, Muhammad Israr ${ }^{5}$ and Raza \\ Ullah $^{5}$ \\ 1. Department of Economics, Karakoram International University Gilgit - Baltistan, Pakistan \\ 2. Nuclear Institute for Agriculture and Biology, Faisalabad, Pakistan \\ 3. COMSATS Institute of Information Technology, Vehari, Pakistan. \\ 4. Department of Plant Protection, Faculty of Agricultural Sciences, Ghazi University, Dera Ghazi Khan, Pakistan. \\ 5. The University of Agriculture, Peshawar, Khyber Pakhtunkhuwa, Pakistan \\ *Corresponding author's email: sadiqhashmi6@gmail.com
}

Citation

Muhammad Sadiq Hashmi, Muhammad Asif Kamran, Khuda Bakhsh, Muhammad Amjad Bashir, Muhammad Israr and Raza Ullah. Socio-economic factors and their influences on scale efficiency of wheat farms. Pure and Applied Biology. Vol. 4, Issue 4, 2015, pp 543-550. http://dx.doi.org/10.19045/bspab.2015.44013

\begin{tabular}{lll}
\hline \hline Received: 29/07/2015 & Revised: 05/11/2015 & Accepted: 14/11/2015 \\
\hline
\end{tabular}

\section{Abstract}

Socio-economic factors play a significant role in agricultural production processes and their estimation is important for better understanding of the factors contributing to agricultural production. Scale Efficiency (SE) can be affected by a wide range of farm assets and socioeconomic factors. The present paper examines SE of wheat growers using primary data and employing Data Envelopment Analysis (DEA) method. We used various socio-economic factors having impact on scale efficiency. They include type and size of farms, machinery used, education, age, farming experience, and working patterns of the target farmers. Significant determinants of scale efficiency are type and size of wheat farms. The results of the study can be used for policy formulation to enhance productivity of farming groups with varying endowments.

Keywords: Agricultural farms categories; Agricultural machinery; Farm size; Farmers' age; Academic qualification; Farming experience; Data envelopment analysis.

\section{Introduction}

Pakistan's economy is agriculturally based and the agriculture sector contributes about $21 \%$ to the country's GDP and employs about $45 \%$ of the total work force, mostly residing in the rural areas. Wheat, rice, maize, cotton and sugarcane are the most important crops and wheat alone contributes about $10 \%$ to the value added in agriculture and $2.2 \%$ to the GDP covering about 8.6 million ha with annual grain production of 23 million tons
[1]. The major wheat growing area is in the irrigated plains of the Indus basin comprising the provinces of Punjab and Sindh. Pakistan's wheat demand is increasing for ever increasing population.

In order to meet the growing need of wheat, efficient production is much desired. A number of factors need to be considered for sustainable and efficient crop production including socioeconomic, environmental, infrastructure, markets, and government 
policies [2]. Production efficiency can be increased by the best use of resources and adoption of the latest technology. The most efficient farmers would choose that input bundle which results in a maximum feasible bundle of output(s) or such farmers would go for choosing a smallest possible input(s) bundle that produces a fixed output level. Third option is that farmers would choose some combination of the above two options. Thus it is critical in finding bundles of inputs resulting in the better efficiency. The present study contributes in the existing literature on efficiency by determining scale efficiency of wheat growers along with its determinants.

Different concepts of efficiency viz. technical efficiency (TE), scale efficiency (SE), and allocative efficiency (AE) are widely used in analysis of agricultural production systems. SE, by definition, is the ratio of $\mathrm{TE}$ (constant return to scale) to $\mathrm{TE}$ (variable return to scale) whereas. TE is defined as comparison of observed and optimal values of all inputs and outputs in the production process [3]. By employing this concept, a production unit is technically inefficient when maximum possible output is not attained, or a give output is not attained by minimum inputs [3].

In current study, the estimation of SE has been done by constant and variable returns to scale. SE gives better information about production efficiency because in case of $\mathrm{TE}$ estimation, either variable returns to scale or constant returns to scale are considered. Moreover, farm size in relationship with the efficiency is more relevant to the concepts of SE instead of TE or AE [4]. This study, based on the above given justification, has employed SE as efficiency measuring criteria.

The present study is designed to estimate scale efficiency and examine the effects of various socio-economic characteristics of wheat growers on scale efficiency. Due to significance of the wheat crop as major staple crop and livelihood source of farmers, the study have important insights for farmers, researchers, and policy makers.

\section{Materials and Methods}

We used primary data collected in 2012 by employing a well-structured and pre-tested questionnaire. Information on wheat output and three input variables including; land, fertilizers and chemicals from 142 farmers in two districts (Dera Ghazi Khan and Rahim Yar Khan) in south Punjab, Pakistan was collected from the selected respondents. All of the variables were measured in absolute values and in international standard units. Output was recorded in kilograms while the input variables: land was recorded in acres; total fertilizers were recorded in kilograms; total chemicals were recorded as total number of acres sprayed. In addition to input and output variables, we also collected information on socio-economic characteristics of farm and farmers.

\section{Specification of socio-economic factors}

Agriculture Farm Type (AFT)

1. Owners - all of the cultivated land owned

2. Owner-renters - partially owned land and partially rented land under cultivation.

3. Renters - Cultivated land being rented. Agricultural Farm Machinery (AFM)

1. Ownership of tractor and other major farm machinery.

2. Farmers without owned tractor and machinery

Agricultural Farm Size (AFS)

1. Small farmers -less than 5 acres land

2. Medium farmers-farmers having land 5 to 25 acres.

3. Large farmers - farmers with landholding of above 25 acres.

Farmers' age

1. Young farmers - age group of 18 to 30 years.

2. Middle aged - age group of 31 to 45 years.

3. Old aged - farmers above 45 years. 
Pure Appl. Biol., 4(4): 543-550, December- 2015 
Farmers' qualification

1. Illiterate/Uneducated -0 or less than 5 years of schooling.

2. Basic education -of 5 to 9 years of schooling.

3. High school or college level education

4. University education

Farmers' experience

1. Less experience -0 to 5 years.

2. Average experience -6 to 20 years.

3. Highly experienced - more than 20 years.

Working style/category

1. Full time-full time

2. Part time - part time

\section{Data analysis}

The study undertakes multiple analysis of different factors of production. Three inputs namely, land (in acres), fertilizers application (total quantity), and chemicals (total quantity) and output namely wheat grain were taken to estimate the SE of the selected wheat farms. Outliers were identified using Statgraphics software. STATA was used to tackle issues of multicolinearity and heteroscedasticity in data. DEA-Max software was used for the measurement of SE of the sampled farms. Kruskal Wallis and Bonferroni comparison tests have been used for impact of socio-economic factors on SE of sampled wheat farms. The detailed methods are given as follows:

\section{Estimation of SE of Wheat Farms by DEA}

SE is both input or output oriented and the fact is considered according to power of the decision maker on production. Farmers, in our case, exert decision over inputs, but have limited power over output(s). Therefore, in this study the input oriented SE has been considered. Therefore DEA (non-parametric) have been used and the efficiency scores are in range of 0 to 1 . DEA model are widely used and seminal work by some of the most prominent researchers in literature $[5,6,7]$. DEA uses its basic assumptions of the output of the most efficient group of farms within the sample to estimate the potential output. $\mathrm{SE}$ is the ratio of input oriented TE $\left(\mathrm{TE}^{\mathrm{i}}\right)$ to output oriented TE $\left(\mathrm{TE}^{\mathrm{o}}\right)$. To calculate $\mathrm{TE}^{\mathrm{i}}$, $\mathrm{TE}^{\mathrm{o}}$, and SE following models $(1,2 \& 3)$ have been used in this study.

\section{Model 1: Estimation of TE}

Let us consider:

$\mathrm{x}^{\mathrm{j}}=\left(\mathrm{x}_{1}{ }^{\mathrm{j}}, \mathrm{x}_{2}{ }^{\mathrm{j}}, \mathrm{x}_{3}{ }^{\mathrm{j}}, \ldots . ., \mathrm{x}_{\mathrm{n}}{ }^{\mathrm{j}}\right)$ is taken as the bundle of $\mathrm{n}$ inputs applied by farmers whereas $\mathrm{y}^{\mathrm{j}}=\left(\mathrm{y}_{1}{ }^{\mathrm{j}}, \mathrm{y}_{2}{ }^{\mathrm{j}}, \mathrm{y}_{3}{ }^{\mathrm{j}}, \ldots . . \mathrm{y}_{\mathrm{m}}{ }^{\mathrm{j}}\right)$ shows the bundle of ' $m$ ' outputs obtained by farmer $\mathrm{j}(\mathrm{j}$ $=1,2,3, \ldots \ldots, \mathrm{N})$. Now consider that the observed farms/farmers are ' $\mathrm{k}$ ' and our interest is to examine the TE of farm/farmer ' $k$ '. The observed input-output bundle of farm ' $\mathrm{k}$ ' is $\left(\mathrm{x}^{\mathrm{k}}, \mathrm{y}^{\mathrm{k}}\right)$. its mathematical form can be written as:

$\max \varphi$ s.t.

$$
\begin{aligned}
& \sum_{J=1}^{N} \lambda_{j} x_{i j} \leq x_{i k} \quad(i=1,2, \ldots ., n) ; \\
& \sum_{J=1}^{N} \lambda_{j} y_{r j} \geq \varphi y_{r k} \quad(r=1,2, \ldots \ldots, m) ; \\
& \sum_{J=1}^{N} \lambda_{j}=1 ; \lambda_{j} \geq 0 \quad(j=1,2, \ldots \ldots ., N) ; \\
& \varphi \text { unrestricted }
\end{aligned}
$$

Hence TE of farm k would be measured by $\tau_{\mathrm{k}}=1 / \varphi^{*}$

$\lambda$ shows efficiency for each farm $\mathrm{j}, \varphi$ indicates measure of technical efficiency whereas $\varphi^{*}$ represents optimum solution of DEA mentioned above.

\section{Model 2: Estimation of output and input oriented TE}

Production possibility set can be better constructed using sample data set D where D is equal to $\left\{\left(\mathrm{x}^{\mathrm{j}}, \mathrm{y}^{\mathrm{j}}\right) ; \mathrm{j}=1,2,, 3 \ldots, \mathrm{N}\right\}$. Production possibility set ' $\mathrm{S}$ ' for the sample estimate can be written as:

$\mathrm{S}=\left\{(\mathrm{x}, \mathrm{y}): \mathrm{x} \geq \Sigma^{\mathrm{N}_{\mathrm{j}=1}} \lambda_{\mathrm{j}} \mathrm{x}_{\mathrm{j}} ; \mathrm{y} \leq \Sigma^{\mathrm{N}_{\mathrm{j}=1}} \lambda_{\mathrm{j}} \mathrm{y}_{\mathrm{j}} ;\right.$

$\left.\sum_{\mathrm{j}=1} \lambda_{\mathrm{j}}=1 ; \lambda_{\mathrm{j}} \geq 0(\mathrm{j}=1,2,3 \ldots, \mathrm{N})\right\}$

Now we consider a measure of output oriented $\mathrm{TE}\left(\mathrm{TE}^{\mathrm{O}}\right)$ with observed input and 
output bundle $\left(\mathrm{x}^{\mathrm{k}}, \mathrm{y}^{\mathrm{k}}\right)$ after finding the TE of farm. It can be given as

$\tau^{\mathrm{y}}{ }_{\mathrm{k}}=1 / \varphi^{*} \quad$ where $\varphi^{*}=\max \varphi:\left(\mathrm{x}^{\mathrm{k}}, \varphi \mathrm{y}^{\mathrm{k}}\right)$

$\epsilon \mathrm{S}$

Equation 4 gives us output oriented $\mathrm{TE}^{\mathrm{O}}$.

Considering the objective of input conservation, the suitable measure for determining efficiency of farm ' $\mathrm{k}$ ' is $T \mathrm{TE}^{\mathrm{i}}$ i.e. input oriented technical efficiency.

$\tau^{\mathrm{x}}{ }_{\mathrm{k}}=\theta^{*}=\min \theta:\left(\theta \mathrm{x}^{\mathrm{k}}, \mathrm{y}^{\mathrm{k}}\right) \in \mathrm{S}$

Mathematically, $\mathrm{TE}^{\mathrm{i}}$ can be written as: $\min \theta$ s.t.

$\mathrm{N}$

$\sum_{J=1} \lambda_{j} x_{i j} \leq \theta x_{i k} \quad(i=1,2, \ldots \ldots, n) ;$

$\mathrm{N}$

$\sum \lambda_{\mathrm{j}} \mathrm{y}_{\mathrm{rj}} \geq \mathrm{y}_{\mathrm{rk}} \quad(\mathrm{r}=1,2, \ldots \ldots ., \mathrm{m})$;

$\mathrm{N}$

$\underset{J=1}{\sum} \lambda_{j}=1 ; \lambda_{j} \geq 0(j=1,2, \ldots \ldots ., N) ; \theta$

Unrestricted

Where $\theta$ shows input oriented efficiency measure.

Estimation of TE on the basis of returns to scale

As indicated in equation (3), returns to scale is a property of the frontier of the production possibility set ' $S$ ' and shows that small equiproportionate increment in all inputs in the production process results in more than proportionate increase in output(s) along the production possibility frontier. Constant returns to scale (CRS) prevail, when increase in inputs results in an equal increase in outputs and the diminishing returns to scale persist when an increase in inputs results in lesser proportionate increase in output. Technology may exhibits returns to scale along the different segments of the frontier and this gives rise to concept of variable returns to scale (VRS). If CRS prevails along the frontier, the definition of the production possibility Set (S) and the resulatnt measure of the TE will be different in such assumption [8]. The assumption the corresponding production possibility set under CRS will be: $\mathrm{S}^{\mathrm{c}}=\left\{(\mathrm{x}, \mathrm{y}): \mathrm{x} \geq \Sigma^{\mathrm{N}_{\mathrm{j}=1}} \lambda_{\mathrm{j}} \mathrm{x}^{\mathrm{j}} ; \mathrm{y} \leq \Sigma^{\mathrm{N}_{\mathrm{j}=1}} \lambda_{\mathrm{j}} \mathrm{y}^{\mathrm{j}} ; \lambda_{\mathrm{j}}\right.$ $\geq 0(j=1,2,3 \ldots ., N)\}$

In this case, the constraint $\Sigma^{\mathrm{N}_{\mathrm{j}=1}} \lambda_{\mathrm{j}}=1$ has been removed from the production possibility set ' $S$ ' as given in the equation (3). In the above set, 'c' indicates the CRS assumption of the model.

\section{Model 3: Estimation of SE}

The SE measure is the ratio of $\mathrm{TE}_{\mathrm{crs}}$ to the TE $_{\text {vrs. }}$ For detail see [8]. Symbolically, SE can be presented as

$\mathrm{SE}=\mathrm{TE}_{\mathrm{crs}} / \mathrm{TE}_{\mathrm{vrs}}$

Determination of Effects of SocioEconomic Factors on SE of Wheat Farms After SE scores estimation, next step is to determine how different factors influence SE. As the data used in the test can be nominal, categorical, ordinal etc and statistical tests are selected based on type of data. According to [9], Kruskal-Wallis test can be used for nominal variable non-normal distribution or it is used when one variable in the data set is nominal and one other is ranked variable. Kruskal-Wallis test will be used in our analysis as there is one nominal and one ranked variable. As we have more groups for comparison of SE, Bonferroni comparison test is used for sake of comparison of pair of ranks.

\section{Results and Discussion}

Frequency distribution of scale efficiency of wheat growers is given in Figure 1. Farms attaining SE in the range of 0.9 to 1.0 are 112 in number and the mean SE is found to be 0.934. The mean SE implies that on the average wheat growers have better efficiency because a few farms fall in the smaller range of efficiency. In the following, the influences of socio-economic factors on SE of wheat farms have been given. 
Fig. 1. Frequency distribution of SE of wheat farms

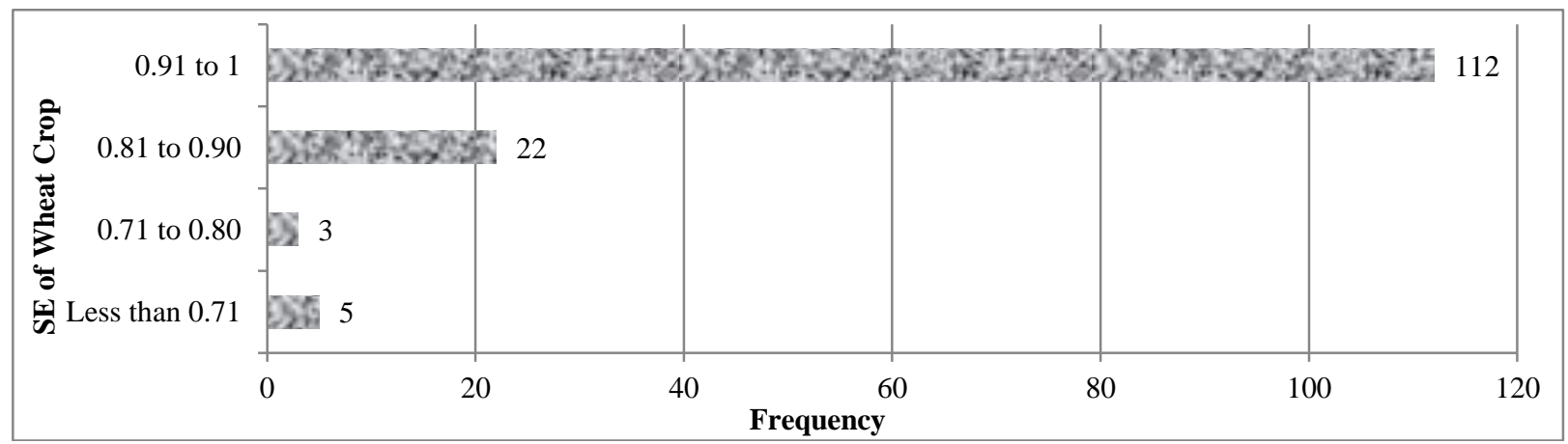

\section{a. Effects of AFT on SE of wheat farm}

Results showing the effects of AFT on the SE of wheat farms are given in Table 1. Findings show that the maximum mean SE score for the owner-renters was 0.972 whereas for owners and renters, it was 0.922 and 0.963 respectively. Statistical test showed that the difference among the groups is statistically significant. Thus it can be argued that the renters' farms performed better than the owners' farms. Further AFT based on ownership of farm was found to have a negative influence on the SE. The logic is that the renters may be farmers who choose farming as a profession along with availability of family labor and other resources used in agriculture production. These results are similar to the findings of $[10,11]$.

Table 1. SE of wheat farms and socio-economic factors

\begin{tabular}{|c|c|c|c|c|c|c|c|}
\hline \multirow{2}{*}{ Factors } & \multirow[b]{2}{*}{ Type/Levels } & \multicolumn{4}{|c|}{ Kruskal Wallis Test } & \multicolumn{2}{|c|}{$\begin{array}{l}\begin{array}{l}\text { Bonferroni comparison } \\
\text { test }\end{array} \\
\end{array}$} \\
\hline & & $\begin{array}{l}\text { Farm } \\
\mathrm{s}\end{array}$ & $\begin{array}{l}\text { Mean } \\
\text { SE }\end{array}$ & $\chi^{2}$ & $\begin{array}{l}\text { Prob > } \\
\chi 2\end{array}$ & Differences & Prob. \\
\hline \multirow{3}{*}{ Farm type } & Owners & 104 & 0.922 & \multirow{3}{*}{9.087} & \multirow{3}{*}{0.011} & $0.050(1,2)$ & 0.009 \\
\hline & Owner-Renters & 24 & 0.972 & & & $0.042(1,3)$ & 0.143 \\
\hline & Renters & 14 & 0.963 & & & $-0.008(2,3)$ & 1.000 \\
\hline \multirow{2}{*}{$\begin{array}{l}\text { Farm } \\
\text { machinery }\end{array}$} & $\begin{array}{l}\text { Farms without } \\
\text { Tractors }\end{array}$ & 104 & 0.927 & \multirow{2}{*}{0.008} & \multirow{2}{*}{0.930} & \multirow{2}{*}{$0.028(1,2)$} & \multirow{2}{*}{0.048} \\
\hline & \begin{tabular}{|l|} 
Farms with \\
Tractors \\
\end{tabular} & 38 & 0.955 & & & & \\
\hline \multirow{3}{*}{ Farm size } & Small & 47 & 0.883 & \multirow{3}{*}{3} & \multirow{3}{*}{0.001} & $0.078(1,2)$ & 0.000 \\
\hline & Medium & 84 & 0.961 & & & $0.071(1,3)$ & 0.005 \\
\hline & Large & 11 & 0.954 & & & $-0.007(2,3)$ & 1.000 \\
\hline \multirow{3}{*}{ Farmers' age } & 18 to 30 Years & 34 & 0.934 & \multirow{3}{*}{0.233} & \multirow{3}{*}{0.890} & $-0.004(1,2)$ & 1.000 \\
\hline & 31 to 45 Years & 80 & 0.930 & & & $0.015(1,3)$ & 1.000 \\
\hline & 46 to 65 Years & 28 & 0.949 & & & $0.019(2,3)$ & 0.753 \\
\hline \multirow{2}{*}{$\begin{array}{l}\text { Farmers' } \\
\text { qualification }\end{array}$} & Uneducated & 22 & 0.922 & \multirow[b]{2}{*}{3.165} & \multirow[b]{2}{*}{0.367} & $0.014(1,2)$ & 1.000 \\
\hline & \begin{tabular}{|l|} 
Basic Level \\
Education
\end{tabular} & 67 & 0.936 & & & $0.020(1,3)$ & 1.000 \\
\hline
\end{tabular}




\begin{tabular}{|c|c|c|c|c|c|c|c|}
\hline & $\begin{array}{l}\text { High School or } \\
\text { College } \\
\text { Level Education }\end{array}$ & 43 & 0.941 & & & $0.002(1,4)$ & 1.000 \\
\hline & $\begin{array}{l}\text { University } \\
\text { Education }\end{array}$ & 10 & 0.924 & & & $0.006(2,3)$ & 1.000 \\
\hline & - & - & & & & $-0.012(2,4)$ & 1.000 \\
\hline & - & - & & & & $-0.018(3,4)$ & 1.000 \\
\hline \multirow{3}{*}{$\begin{array}{l}\text { Farmers' } \\
\text { experience }\end{array}$} & 0 to 5 years & 8 & 0.904 & \multirow{3}{*}{4.471} & \multirow{3}{*}{0.107} & $0.025(1,2)$ & 1.000 \\
\hline & 6 to 20 years & 82 & 0.929 & & & $0.045(1,3)$ & 0.362 \\
\hline & $\begin{array}{l}\text { More than } 20 \\
\text { years }\end{array}$ & 52 & 0.948 & & & $0.019(2,3)$ & 0.452 \\
\hline \multirow{2}{*}{$\begin{array}{l}\text { Working } \\
\text { Style }\end{array}$} & Full Time & 134 & 0.940 & \multirow[b]{2}{*}{4.471} & \multirow[b]{2}{*}{0.345} & \multirow[b]{2}{*}{$-0.104(1,2)$} & \multirow[b]{2}{*}{0.000} \\
\hline & Part Time & 8 & 0.836 & & & & \\
\hline
\end{tabular}

\section{b. Effects of AFM on SE of wheat farm}

Results show that tractor ownership has significant impact on SE of wheat growers as farmers having tractor are found to have SE of 0.955 compared to their counterparts (0.927). Kruskal Wallis test shows insignificant difference but Bonferroni comparison test shows that this difference is significant.

\section{c. Effects of AFS on SE of wheat farm}

As per Kruskal Wallis and Bonferroni tests, we found that medium farms have significantly higher SE score (0.961) than small farms (0.883) and large farms (0.954). So we conclude that with an increase in AFS, SE score of wheat growers also increases.

\section{d. Effects of farmers' age on SE of wheat farm}

Age of the farmers is non-linearly related with SE as middle aged farmers have a minimum mean SE score of 0.930 compared to old farmers (0.949) and young farmers (0.934). However, the difference is statistically non-significant.

\section{e. Effects of farmers' qualification on SE of wheat farm}

Like farmers' age, education of farmers is also positively non-linearly related with SE. Farmers with qualification of high school or college have a mean SE score of 0.941, with basic education have 0.93 , with university education 0.924 and with no education 0.922 . Test statistics show that the difference in SE based on education is statistically nonsignificant in the present study. Reason lies in the fact that highly educated farmers are not actively involved in farming while the uneducated or less educated farmers are practically involved in farming so they are more efficient by employing family labor. As per [12], effects of education are much likely to be positive in modern agriculture environments than in traditional ones.

\section{f. Effects of farmers' experience on SE of wheat farm}

Farmers' experience is positively and linearly related with SE in wheat production. The most experienced farmers are found to have SE score of 0.948 compared to small and medium experienced farmers with SE scores of $0.904 \&$ \& 0.929 , respectively. However, the difference is statistically nonsignificant based on the statistical tests.

\section{g. Effects of farmers' working style on SE of wheat farm}

Farmers who were fully involved in farming were more efficient than those who were partially involved in farming as the respective mean SE scores were found to be 0.940 and 0.836 . We used statistical tests to determine significant difference, we found that the SE score for these two types of 
farmers was non-significant while using Kruskal test whereas Bonferroni test showed the difference as statistically different from zero.

\section{Conclusion}

The study concludes that the SE is significantly influenced by farm type and farm size the results show that the renters' wheat farms have better SE as compared to owners' farms. Moreover, the large wheat farms are more efficient than smaller ones if the farm size is considered. Moreover, farmers owning farm machinery are more efficient than the renters (non-owners). The results of the study show that there is no significant effect of all of the four social factors. The inefficiency of owner farmers may be attributed to farmers' practice of cultivating wheat as an additional crop to cotton as the latter is harvested as a source of cash and former for additional income and family wheat requirement. Moreover, the large owners are more efficient as they can afford machinery and other inputs needing considerable investment while the small holders mostly sow wheat as subsistence agriculture practice. The access to heavy investment machinery can be reduced through introduction of community level ownership of machinery and through building social capital to promote communal level organization to foster such collective action. Moreover, policy makers may also introduce schemes at village level to provide machinery to small holders at affordable prices. Small farmers are unable to reap benefits of many of the governmental schemes for loans for machinery and the community level lending schemes can help small holders to give collateral and get machinery.

\section{Authors' contributions}

Collected data, coordinated over all working of paper and wrote the conclusion: MS Hashmi. Wrote introduction and literature review: MA Kamran. Conducted the statistical analysis: K Bukhsh. Interpreted the results: MA Bashir. Proof reading and helped in interpreting the results: M Israr. Helped in analysis of data and over all organization of the study: R Ullah.

\section{References}

1. Pakistan Bureau of Statistics (2014). Agriculture Statistics. Table -1 Area and production of important crops.

2. Passel SV, Lauwers L, \& Huylenbroeck GV (2006). Factors of farm performance: an empirical analysis of structural and managerial characteristics. Cuases and Impacts of Agricultural Structures. p. 3-22.

3. Sadoulet E, \& Janvry AD (1995). Quantitative development policy analysis. London: The John Hopkins University Press. 1995. [Viewed on 2312-2011]. Available on: <http://www.dipsa.unifi.it/romano/ASP/ Sadoulet_de\%20Janvry\%20QDPA.pdf $>$

4. Zyl JV, Binswanger $\mathrm{H}$, \& Tbirtle $\mathrm{C}$ (1995). The relationship between farm size and efficiency in South African agriculture. Policy research working paper 1548. The World Bank. Agriculture and Natural Resources Department Office of the Director. November 1995.

5. Debreu G (1951). The Coefficient of Resource Utilization, Econometrica, 19, 273-292.

6. Farrel MJ (1957). The measurement of Productive Efficiency, Journal of the Royal Statistical Society, Series A, CXX, Part 3, 253-290.

7. Shephard RW (1970). Theory of cost and production function, Princeton University.

8. Ray SC (2004). Data Envelopment Analysis: Theory and Techniques for Economics and Operation Research. Cambridge University Press, New York

9. McDonalld JH (2013). Handbook of Biological Statistics (3rd ed.). Sparky 
House Publishing, Baltimore, Maryland. Available at: http://www.biostathandbook.com/krusk alwallis.html.

10. Helfand SM, \& Levine ES (2004). Farm size and the determinants of productive efficiency in the Brazilian Center-West. Agricultural Economics 31. 2004. p. 241-249. doi:10.1016/j.agecon.2004.09.021.

11. Mathijs E, \& Vranken L (2001). Human capital, gender and organization in transition agriculture: measuring and explaining the technical efficiency of Bulgarian and Hungarian farms. PostCommunist Economics 13(2), 171-187. [Viewed on 13-08-20012]. Available on: <http://www.tandfonline.com/doi/abs/1 0.1080/14631370120052654>.

12. Lockheed ME, Jamison DT, \& Lau LJ (1980). Farmer Education and Farm Efficiency: A Survey, Economic Development and Cultural Change, University of Chicago Press. Vol. 29(1), pages 37-76. 